\title{
CV. Observations on the peculiar alternations in the colour of Antares, or the bright star in the heart of the scorpion, compared with that of other stars
}

\section{Thomas Forster Esq.}

To cite this article: Thomas Forster Esq. (1817) CV. Observations on the peculiar alternations in the colour of Antares, or the bright star in the heart of the scorpion, compared with that of other stars , Philosophical Magazine, 49:230, 452-454, DOI: 10.1080/14786441708637948

To link to this article: http://dx.doi.org/10.1080/14786441708637948

曲 Published online: 27 Jul 2009.

Submit your article to this journal $\pi$

山 Article views: 2

Q View related articles 


\section{Olservations on the peculiar Alternations in the Colour}

senger was quite new when we left this place, and had not been used more than five or six times."

Sheerness, Feb 9, 1816.

(Signed)

To Lieut. Shuldham, $6^{\circ} \mathrm{c}$.

G. E. Powel, First Lieut. Brig Cordelia.

\section{Certificate.}

I hereby certify, that I have seen Lieut. SHucdnam's contrivance for the application of additional men to a capstan, when it is required to have a great strain, and have no doubt of its efficacy; and as it is not attended with any trouble or expense, I think the invention, when known, will certainly be generally adopted, its simplicity and utility being so obvious.

April 26, 1816. (Signed) A. Brown, Commander, R.N.

Reference to the Engraving of Lieut. ShulnHaM's improved Method of working a Capstan. Plate V. fig. 2.

In addition to the usual manner of placing men between the capstan bars, the ends of the bars should have notches or gaps made in them, in which an endless rope, $A B$, is received, and passes through two pulley blocks, $C D$; thus forming two straight lines, along which men being placed, can act by pulling the ropes in the most efficacious manner upon the capstan.

CV. Olservations on the peculiar Alternations in the Colour of Aniares, or the bright Star in the Heart of the Scorpion, compared with that of other Stars. By Thomas Forster, Esq.

$S_{1 \mathrm{R},-}-I_{\text {Havr heretofore had occasion to notice the mutations }}$ in the colour of the light of some of the larger fixed stars, and have communicated such ohservations through the medium of your Magazine. I have now to commemorate the great, and, I may say, unusual brilliancy of this phænomenon observed last night in the star Antares, which has afforded an opportunity, during the serenity of a long summer's night, of minutely observ. ing and defining it, together with the concomitant twinkling. Ahout $9^{\prime} 35^{\prime}$ I first noticed it. The star twinkled a great deal; ; and this motion called twinkling, seems to consist of successive dilatation and brightness, and of apparent contraction and dullness, alternating with each other. The alternating colours are deep red and bright white with a tinge of blue. To be more explicit, I have compared the red colour to the colour of copper flings ignited with gunpowder in the pyrotechnical Jerbs, and the white colour to ignited steel filings. The red colour happens in general just at, or a little before, the maximum of 
the twinkle, or bright apparent dilatation of the star. It seems to occur only once in the course of five or six dilatations, though now and then oftener: I could not distinetly ascertain any re. gular periods of it. The intervening colour of the light hardly varied, except in the brilliancy of the twinklings. Being at Tunbridge Wells, on very high ground, I watched the phænomenon during great part of the night : sometimes the red colour was very intense and bright, and was followed by an almost disappearance of the star by the apparent contraction. I do not know whether I use terms sufficiently explanatory; bus it is difficult, in describing phænomena not much treated of before, to select the most appropriate terms. I hope I shall convey to the reader a tolerably clear idea of the fact, and that corresponding observations will be made. I noticed this appearance six or seven years ago, in the month of September; but it has certainly increased since that time. I may observe also that the twinkling of Antares is greater than that of any other star visible at the same time. As the above-mentioned alternation of colour is visible in several other stars, I have noticed them, with some of the peculiarities attending the changes of their light.

1. Antares in nean longitude $8^{\circ} 7^{\circ} 14^{\prime} 24^{\prime \prime}$; mean south latitude $4^{\circ} 30^{\prime} 48^{\prime \prime}$. Has the greatest twinkling, and most intense red colour alternating with white in the most irregular manner.

2. Betalgeus, or a Orionis, mean longitude $2^{2} 26^{\circ} 14^{\prime} 26^{\prime \prime}$; south latitude $16^{\circ} 3^{\prime} 50^{\prime \prime}$. Alternations of red and yellowish, not so distinctly marked as the last, and the times of the red bear a greater proportion to those of the yellow.

3. Aldebaran, or a Tauri, longitude $2^{\mathrm{s}} 7^{\circ} 16^{\prime} 26^{\prime \prime}$; south latitude 2" $29^{\prime} 16^{\prime \prime}$. Alternation still less conspicuous.

As the above stars are in very different places in the heavens, and as the stars about them do not show the least alternation; so I think the change of colour cannot depend on any thing in our atmosphere, but must attend some alteration going on in the alternating star. I must observe also, that this phæenomenon is seen only in the red stars; it is faintly observable in Arcturus, but wholly imperceptible in Lyra, or the bright star in the Eagle. In Syrius it is faintly observable, but perhaps the least so of all. Syrius is reported by the old astronomers to have been a red star; and perhaps the alternation I allude to, may be somehow connected with the more permanent change of colour of varying stars. The phrnomenon is seen with refracting (and probably also reflecting) telescopes, and certainly deserves the attention of astronomers. I am, sir, \&c.

Spa Lodge, Tunbridge Wells,

Thomas Forster. June 20, 1817. 
P.S. I saw the phænomenon alluded to in the Joumals, in Leo, in longitude $4^{\prime \prime} 27^{\circ} 2 l^{\prime} 50^{\prime \prime}$. It appeared in the telescope just above Regulus, like a small yellow star.

\section{Notices respecting New Books.}

The Philosophical Transactions of the Royal Society of Londun for 1817, Part I. has just been published, and contains the following papers :

I. As Account of the Circulation of the Blood in the Class Vermes of Linnæus, and the Principle explained in which it differs from that in the higher Classes. By Sir Everard Home, Bart. V.P.R.S. - II. Observations on the Hirudo vulgaris. By James Rawlins Johnson, M.D. F.L.S. \&c.-III. On the Effects of Galvanism in restoring the due Action of the Lutigs. By A. P. Wilson Philip, Physician in Worcester.-IV. An Account of some Experiments on the Torpedo Electrus, at La Rochelle. By John T. Todd, Esq.-V, A Description of a Process by which Corn tainted with Must may be completely purified. By Charles Hatchett, Esq. F.R.S.-Vi. Observations on an astringent Vegetable Substance from China. By William Thomas Brande, Esq. Sec. R.S.-VII. Some Researches on Flame. By Sir Humphry Davy, LL.D. F.R.S. V.P.R S. - VIII. Some new Experiments and Ohservations on the Combustion of gascous Mixtures, with an Account of a Method of preserving a continued Light, in Mixtures of inflammable Gases and Air, without Flame, By Sir H.Davy, LL.D. \&c. \&c.-IX. De la Structure des Vaisseaux Anglais, considérée dans ses dernièrs Perfectionmements. Par Charles Dupin, Correspondant de l'Institut de France, \&c- - X. On a new fulminating Platinum. By Edmund Davy, Esq. Professor of Chemistry, and Secretary to the Cork Institution-XI. On the Parallax of the Fixed Stars. Bv John Pond, Esq. Astronomer Royal, F.R.S. Appendix to Mr. Pond's Paper on Parallax. - XII. An Account of some Fossil Remains of the Rhinoceros discovered by $\mathrm{Mr}$. Whitley in a Cavern inclosed in the Limestone Rock from which he is forming the Break-water at Plymouth. By Sir Everard Home, Bart. V.P. R.S. - Meteorological Journal.

Sir John Sinciarr's Code of Agriculture.

However doubtful or mysterious the art of Agrieulture may have formerly been considered, yet by the varions improvements which have been made in that art, and the great increase of knowledge which has of late years been amașed, the difficulties 